\title{
Barium titanate/polyester resin nanocomposites: Development, structure-properties relationship and energy storage capability
}

\author{
I. A. Asimakopoulos ${ }^{1}$, G. C. Psarras ${ }^{2 *}$, L. Zoumpoulakis ${ }^{1}$ \\ ${ }^{1}$ National Technical University of Athens, School of Chemical Engineering, Section III 'Materials Science and \\ Engineering', Laboratory Unit 'Advanced and Composite Materials', 9-Heroon Polytechniou str., Zografou Campus, \\ Athens 157 73, Greece \\ ${ }^{2}$ Department of Materials Science, School of Natural Sciences, University of Patras, Patras 26505, Greece
}

Received 26 February 2014; accepted in revised form 17 May 2014

\begin{abstract}
Nanocomposite materials based on two different types of polyester matrix (a commercial type and a laboratory produced one) with embedded barium titanate nano-particles were developed and characterized. Structural and morphological characteristics of the produced composite specimens were studied via X-ray diffraction, Fourier transformation infra red spectroscopy, and scanning electron microscopy. Thermal, mechanical and electrical performance was examined via differential scanning calorimetry, bending and shear strength tests, and broadband dielectric spectroscopy, respectively. Mechanical strength appears to reduce with the increase of filler content. Commercial polyester's composites exhibit brittle behaviour, while laboratory polyester's composites exhibit an elastomeric performance. Dielectric data reveal the presence of four relaxation processes, which are attributed to motion of small parts of the polymer chain $(\gamma$-mode), re-arrangement of polar side groups ( $\beta$-mode), glass to rubber transition of the polymer matrix ( $\alpha$-mode) and Interfacial Polarization between the systems' constituents. Finally, the energy storing efficiency of the systems was examined by calculating the density of energy.
\end{abstract}

Keywords: nanocomposites, polyester resin, barium titanate ferroelectric crystal, mechanical properties, structural characterization

\section{Introduction}

The presence of $\mathrm{BaTiO}_{3}$ nano-particles in this type of polyester polymer composites adds to the materials' system performance piezoelectric, ferroelectric and pyroelectric properties. These properties can be exploited in developing 'intelligent' or 'smart'materials. Intelligence, at its most basic level in materials is characterized by three fundamental functions associated with sensing, actuation and control [1]. These fundamental functions are also related with energy conversion mechanisms and information-transfer mechanisms which involve essential concepts at the atomic and molecular levels [2]. The applications of smart materials and structures are expected to be widely diverse, ranging from bio-medical to energy storing devices. A common denominator for the deployment of the most sophisticated class of materials systems, featuring sensors, actuators and microprocessors, will probably be the unstructured environment in which a system should operate properly. Thus the uncertainty associated with the influence of the relevant external stimuli, which govern the system's response relative to the prescribed design, will largely dictate the deployment of smart materials and structures $[2,3]$.

\footnotetext{
*Corresponding author, e-mail: G.C.Psarras@upatras.gr

(C) BME-PT
} 
An outstanding position in the group of electroceramics is given to composite materials based on barium titanate. Barium titanate is a wide band gap semiconductive ferroelectric material with perovskite structure which has been of practical importance for over 60 years due to its specific electrical properties. Barium titanate's great significance is expressed in its applications, which include ceramic capacitors, PTCR thermistors (positive temperature coefficient resistors/thermistors or posistors), piezoelectric sensors, optoelectronic devices, transducers, actuators etc. [4-10]. Furthermore, it is being applied as a capacitive material in dynamic random access memories (DRAM) in integrated circuits. DRAM applications require both high dielectric constant and good insulating properties [10]. Semiconductor memories such as dynamic random access memories (DRAM's) and static random access memories (SRAM's) currently dominate the market. However, the disadvantage of these memories is that they are volatile, i.e. the stored information is lost when the power fails. The non-volatile memories available at this time include complementary metal oxide semiconductors (CMOS) with battery backup and electrically erasable read only memories (EEPROM's). These non-volatile memories are very expensive. The main advantages offered by ferroelectric random access memories (FRAM's) include non-volatility and radiation hardened compatibility with CMOS and GaAs circuitry, high speed (30ns cycle time for $\mathrm{read} /$ erase/rewrite) and high density $\left(4(\mu \mathrm{m})^{2} /\right.$ cell size) [11].

Up to now, the most important utility of $\mathrm{BaTiO}_{3} /$ polymer composites is based on their dielectric properties, because of barium titanate's high dielectric permittivity value (high-K material) [12]. Nevertheless serious drawback for this kind of composites is their poor mechanical properties [13]. The latter is related to the brittle nature of the ceramic filler, and to the possibility that distributed ceramic particles could act as stress raisers. Ideally, mechanically robust and processable at ambient temperature, tiny high-k materials could be incorporated within suitable polymers to form composites that combine desired properties of both components [14-16]. Ceramic/polymer nanocomposites should retain advantages emanating from the reinforcing phase, such as high dielectric permittivity, excellent thermal stability and high stiffness in compression, and the polymer matrix, such as low density, flexibility, facile processability, and high dielectric breakdown strength [17]. However, dispersing nano-ceramic particles, such as bariun titanate, in a polymer matrix in order to form a high-k composite, creates an extensive interfacial area, which has a crucial effect on the overall dielectric performance of the system. Therefore, it is necessary to study the dielectric properties, the employed processing route, and the synergy of the composite's constituents before polymer matrix/high-k materials could be exploited in technological applications [18]. Current applications of this type of composites include multilayer ceramic capacitors (MLCC's), thermistors, electro-optic components, integrated capacitors, thin films electronic component materials, acoustic emission sensors, moreover they proved to be useful for the reduction of leakage currents [19]. Additionally, ceramic/ polymer nanocomposite can be exploited in the development of dielectric-based capacitors for energy storage in novel electronics used in electric vehicles, cellular phones, medical devices, wireless personal digital assistants etc. [17, 20]. Embedded nanoinclusions can be considered as a distributed network of nano-capacitors, which can be charged and discharged defining thus an energy storing procedure at the nano-scale level [3, 21]. Furthermore, ceramic/ polymer composites appear to be attractive to researchers, nowadays, because of their simple and convenient manufacturing processes, low cost, enhanced properties and outstanding compatibility with printed wiring board (PWB), such as lower dielectric loss, lower conductivity and leakage current [22].

In this study, novel composite materials have been produced, by combining two types of polyesters, with different chemical raw materials, as the polymer matrix and nano-particles of barium titanate as the reinforcing phase at various loadings. Prepared specimens were then tested by means of different experimental techniques aiming to identify their structural, mechanical, thermal and dielectric properties. Structural characterization took place via a number of experimental techniques (such as scanning electron microscopy-SEM, energy dispersive X-ray spectroscopy-EDAX and infra red spectroscopy via Fourier transformation-FTIR). Thermal, mechanical and dielectric properties were examined by means of differential scanning calorimetry (DSC), three point shear and bending tests and broadband dielectric spectroscopy (BDS), respectively. 


\section{Experimental}

\subsection{Laboratory unsaturated polyester polymerization process}

The polymerization process was held via a polyesterification reaction. This is a polycondensation reaction, which is a typical step-growth polymerization, so water molecules were removed from the reactor by using distillation method with recirculation (vapour reflux reactor) with $2000 \mathrm{~mL}$ capacity. The raw materials that have been used in the polyesterification reaction were maleic and adipic acid in the molar proportion of $60-40 \%$ and ethylene glycol in the molar proportion of $110 \%$ (this ratio refers to the feed ratio of the reactor). These monomers were used with ethylene glycol with $10 \%$ molar excess over stoichiometry, because of the fact that ethylene glycol evaporates during the reaction. Toluene was used as a reflux fluid $(3.5 \% \mathrm{v} / \mathrm{w}$ of total monomers) and hydroquinone was employed as inhibitor $(0.013 \% \mathrm{w} / \mathrm{w}$ of total monomers) [23-25]. The product of the polymerization was the development of the laboratory unsaturated polyester with the code type MA6AA4. For controlling the progress of polymerization, a dynamic temperature profile was used at different final temperature values. Measurements of the generated water quantities versus time, lead to the determination of such stages of the polymerization. So as a consequence, Acid Number (AN) of the final product was determined by titration with $0.5 \mathrm{~N}$ methanolic potassium hydroxide solution and calculated $44 \mathrm{mgKOH} / \mathrm{g}$ polyester, which is an accepted value according to literature [23, 24]. Not only Acid Number but also other kinetic parameters, regarding polymerization process, have been calculated and are exposed in Table 1 (theoretical background is not referred here, as it is thoroughly explained in other works) [23-25]. Except from Acid Number the progress of the polyesterification was studied via the amount of the eliminated water [25, 26]. Time duration of the whole polymerization process was between 6 and $10 \mathrm{~h}$.

Table 1. Kinetic parameters regarding polyesterification polymerization process of laboratory unsaturated MA6AA4 polyester

\begin{tabular}{|c|c|c|c|c|}
\hline \multirow{2}{*}{$\begin{array}{c}\text { U.P. } \\
\text { code type }\end{array}$} & \multicolumn{2}{|c|}{$\mathbf{E}_{\mathbf{a}}$} & \begin{tabular}{c}
$\mathbf{k}_{\mathbf{0}}$ \\
\cline { 2 - 3 }
\end{tabular} & \multirow{2}{*}{$\mathbf{R}^{\mathbf{2}}$} \\
\hline MA6AA4 $/ \mathbf{m o l}]$ & {$\left[\mathbf{k J} \cdot \mathbf{m o l} \mathbf{m o l}^{-\mathbf{2}} \cdot \mathbf{m i n}^{-\mathbf{1}}\right]$} & \\
\hline
\end{tabular}

\subsection{Composite specimens preparation-curing process}

In the unsaturated polyester MA6AA4, in order to be ready for the curing process, it was necessary to add styrene $(30 \% \mathrm{w} / \mathrm{w}$ of the produced amount of polyester) and hydroquinone $(0.03 \%$ of styrene's' quantity) in its liquid form [24]. Afterwards liquid/ solid mixtures (cured system) were prepared by mixing polyester (either commercial polyester type: thixotropic polyester with accelerator, Neotex, Athens, Greece or laboratory-MA6AA4 one), barium titanate nano-particles (Sigma Aldrich, Taufkirchen, Germany) (with mean diameter in the range: 30-50 nm), methyl ethyl ketone peroxide (MEKP) as initiator and cobalt (II) naphthenate (CoNp) as accelerator. The proportion of MEKP was $3 \% \mathrm{v} / \mathrm{w}$ and CoNp was $1 \% \mathrm{v} / \mathrm{w}$ (both proportions are referred on polyester's quantity) [23-25]. The specimen's content in barium titanate ranged from $0-20 \% \mathrm{w} / \mathrm{w}$. Mixtures were magnetically stirred for $15 \mathrm{~min}$ approximately and then poured in the closed-type steel moldings. Afterwards moldings were sealed with specific caps and then placed in the thermo-compressor. The mixtures then were cured using compression molding technique. The curing program consisted of two stages. Firstly, nano-composites underlie no pressure at $60^{\circ} \mathrm{C}$ for $15 \mathrm{~min}$, while in the second stage pressure of $8.5 \mathrm{MPa}$ was applied at $60^{\circ} \mathrm{C}$ for $15 \mathrm{~min}$.

\subsection{Structural characterization}

Concerning the study of specimen's surface and the nanoparticle's dispersion in the polymer matrix Scanning Electron Microscopy (SEM) has been used. The employed SEM device is a FEI Quanta 200 (FEI Company, Dawson Creek Drive, Hillsboro, USA), equipped with Element Dispersive X-Ray Analysis (EDAX).

Additionally, the structure of both types of composite systems was examined by means of X-ray diffraction (XRD) scans by means of Siemens D5000 Diffractometer (Siemens, Germany), using a $\mathrm{Cu} \mathrm{K \alpha}$ source, scanning in the range 5 to $120^{\circ}$, with a step of $0.0020^{\circ}$ and a step time of $1 \mathrm{sec}$. XRD measurements were carried out at specimens with $0,5,20 \%$ content in $\mathrm{BaTiO}_{3}$ (for both kinds of composites, either with the commercial polyester as a polymer matrix or the laboratory MA6AA4 one) and pure $\mathrm{BaTiO}_{3}$ nano-powder. 
Chemical bonds of both polyesters and barium titanate, were studied via vibrational spectroscopy and particular by means of infra red spectroscopy via Fourier transformation (FT-IR) (Perkin Elmer FT-IR Spectrum GM-Waltham, Massachusetts, U.S.A.). The measurements are in the form of transmittance versus wavelength in the spectrum region of middle infra red irradiation between 4000 $200 \mathrm{~cm}^{-1}$.

\subsection{Thermal analysis}

A DSC Q200 (TA Instruments, Lukens Drive, New Castle, U.S.A.) Differential Scanning Calorimeter setup operating at a scan rate of $10^{\circ} \mathrm{C} / \mathrm{min}$ was used to characterize thermal transitions of the employed polyester resins and composite systems. Samples were placed within an aluminum crucible, while an empty aluminum crucible was serving as reference material. Temperature was varied from ambient to $200^{\circ} \mathrm{C}$, followed by an isothermal stage at $200^{\circ} \mathrm{C}$ for 1 minute. Afterwards, the cooling process consisted of cooling until $0^{\circ} \mathrm{C}$ (via nitrogen flow) again with a cooling rate of $10^{\circ} \mathrm{C} / \mathrm{min}$. The aim of this characterization was the determination of glass transition temperatures $\left(T_{\mathrm{g}}\right)$ of each specimen. The determination of $T_{\mathrm{g}}$ was carried out via the point of inflexion of the transition.

\subsection{Mechanical characterization}

Composite specimens both with commercial or laboratory polyester matrix were mechanically tested using the three-point method, employing bending (DIN-53452) and shear (ASTM-NORM D 234465T) strength tests [27]. Between these two tests the only difference is that in the shear strength test the distance between the two points was $10 \mathrm{~mm}$, while in the bending strength test was $100 \mathrm{~mm}$. In both of them, the evaluated parameter was the deflection in $\mu \mathrm{m}$. Obtained data were used for the calculation of the shear and bending strength for each sample in MPa [27, 28]. All mechanical tests took place at room temperature $\left(25^{\circ} \mathrm{C}\right)$. Specimens are classified in two types: in the first one the dimensions are $13,5 \mathrm{~cm}$ length, $17 \mathrm{~mm}$ width and $3 \mathrm{~mm}$ thickness (specimens for shear tests) and in the second one the dimensions are $13 \mathrm{~cm}$ length, $10 \mathrm{~mm}$ width and $3 \mathrm{~mm}$ thickness.

\subsection{Dielectric characterization}

Dielectric measurements were conducted by means of Broadband Dielectric Spectroscopy (BDS) in the frequency range of $0.1 \mathrm{~Hz}$ to $1 \mathrm{MHz}$, using an Alpha-N Frequency Response Analyser (Novocontrol Technologies, Hundsagen, Germany). The employed dielectric cell (BDS-1200, Novocontrol) is a parallel-plate capacitor with two gold-plated electrodes. Temperature was controlled via Quatro device, supplied also by Novocontrol, with accuracy $\pm 0.1^{\circ} \mathrm{C}$. Experimental data were obtained by performing isothermal frequency scans, for each examined specimens, from -100 to $160^{\circ} \mathrm{C}$ with a temperature step of $10^{\circ} \mathrm{C}$. The amplitude of the applied test voltage was kept constant at $1000 \mathrm{mV}$. The specimens that underwent such measurements were: 0,5 , 10 and $20 \% \mathrm{w} / \mathrm{w}$ in $\mathrm{BaTiO}_{3}$ content for both kinds of polyester polymer matrices.

\section{Results and discussion}

\subsection{Scanning electron microscopy (SEM) and energy dispersive $\mathrm{X}$-ray spectroscopy (EDAX) characterization}

SEM images depicted in Figure 1, reveal that the dispersion of barium titanate's nano-particles is quite satisfactory for both types of polyesters, because of the absence of extensive barium titanate's agglomerates. However, clusters as well as nano-dispersions can be detected in all studied systems. In relation to specimen's topography, the surface is more smooth and flat without so many micro-cavities for the case of laboratory polyester. Commercial polyester has probably more micro-cavities and bigger agglomerates' diameter because of its' higher viscosity, in comparison to the low viscosity of the laboratory polyester. High viscosity leads to more difficult mixture of the raw materials during the curing process and also in obstruction in filling of the molds. Another parameter which assists the creation of rough surface is the employment of poly(vinyl alcohol) (PVA). Its effect is more evident in composites with commercial polyester resin (Figure 1a). PVA was used as a lubricant of the molding parts, in order to remove easily and without any damage the cured specimens from the mold. Compression molding technique rises temperature and pressure. This fact leads, PVA to create corrugations in the surface of 


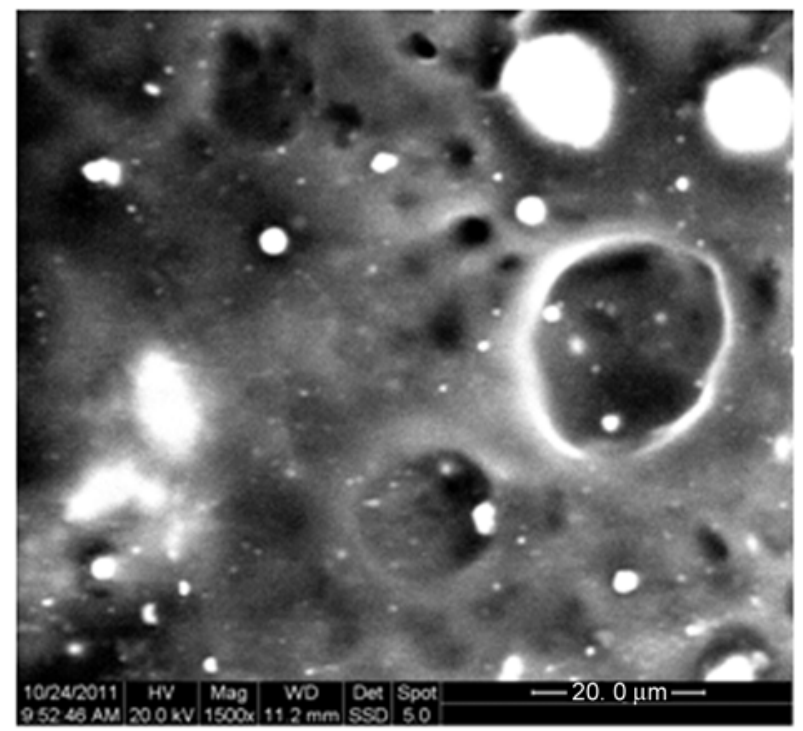

a)

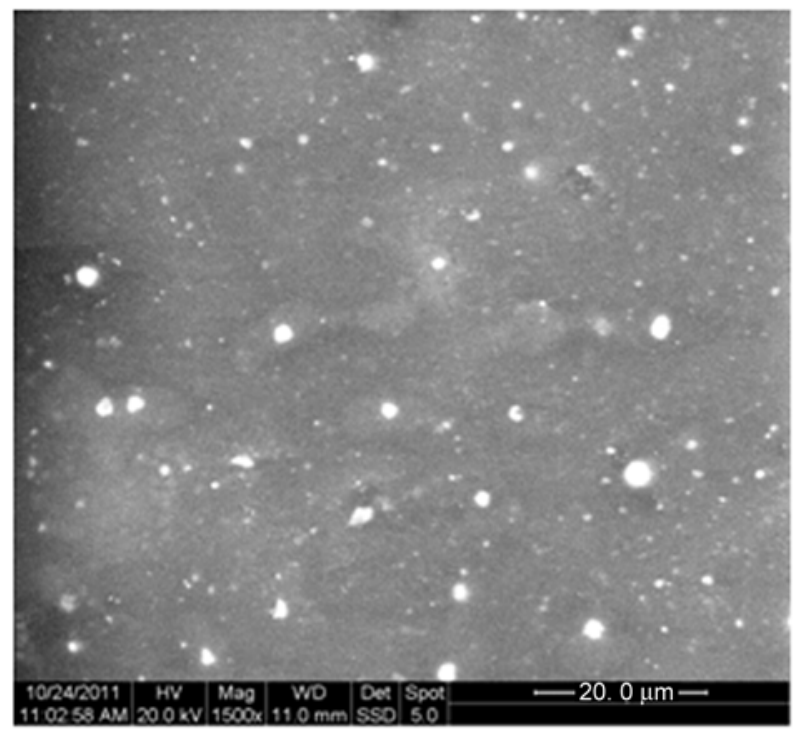

b)

Figure 1. Scanning electron microscopy images from nano-composite specimen with $20 \% \mathrm{w} / \mathrm{w}$ content in $\mathrm{BaTiO}_{3}$ for a magnification of about 1500 times $(\times 1500)$ embedded in: commercial polyester polymer matrix (a), laboratory MA6AA4 polyester polymer matrix (b)

Table 2. Energy dispersive X-ray spectroscopy measurements from nano-composite specimen with $20 \% \mathrm{w} / \mathrm{w}$ content in $\mathrm{BaTiO}_{3}$ embedded in: commercial polyester

\begin{tabular}{|c|c|c|l|l|r|}
\hline Chemical element & $\mathbf{C}(\mathbf{K})$ & $\mathbf{O ( K )}$ & $\mathbf{B a}(\mathbf{L})$ & $\mathbf{T i}(\mathbf{L})$ & Total \\
\hline Proportion in \% (c.p) & 36.81 & 12.98 & 40.48 & 9.73 & 100.00 \\
\hline Proportion in \% (l.p.) & 43.58 & 15.60 & 31.87 & 8.95 & 100.00 \\
\hline
\end{tabular}

the polymer matrix prior being evaporated. Commercial polyester, because of its higher viscosity, traps the initially liquid PVA and as a result the finally evaporated PVA, creates the micro-cavities. On the other hand laboratory polyester with low viscosity helps PVA to evaporate and escape from the specimen easier and quicker without creating cavities.

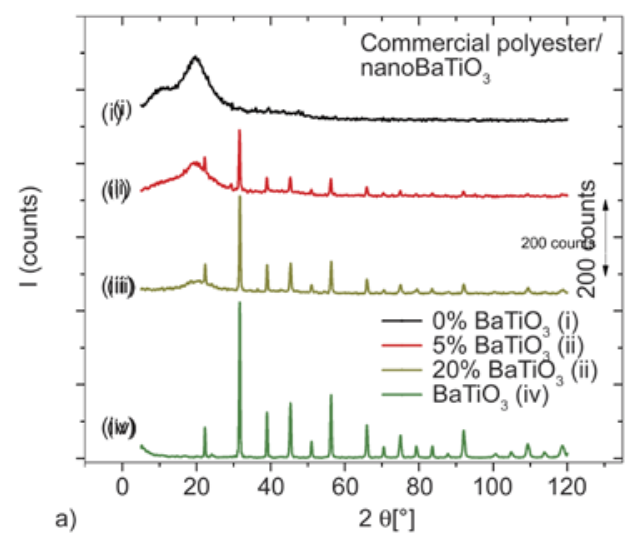

Energy dispersive X-ray spectroscopy (EDAX) measurements (Table 2) detect the presence carbon, barium, oxygen and titanium, as expected. The highest proportion of all detected chemical elements corresponds to carbon, due to the polymer matrix.

\subsection{X-ray diffraction (XRD) characterization}

The obtained XRD spectra of the above mentioned specimens are depicted in Figure 2. Spectra from unfilled specimens exhibit a wide peak at low values of $2 \theta$ angle characteristic for amorphous materials such as the employed polymers. On the other hand $\mathrm{BaTiO}_{3}$ spectrum reveals its crystalline nature via the formed sharp peaks. Plots from the nanocomposites with 5 and $20 \% \mathrm{w} / \mathrm{w}$ content in $\mathrm{BaTiO}_{3}$ include contributions from both constituent materi-

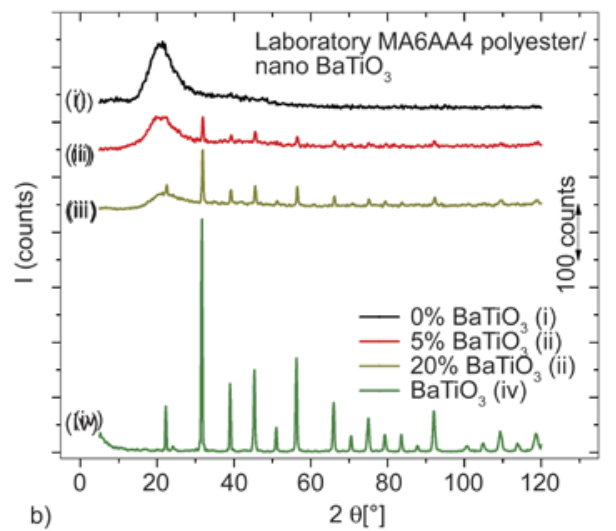

Figure 2. X-ray diffraction spectra from pure $\mathrm{BaTiO}_{3}$ nano-particles and specimens with $0,5,20 \% \mathrm{w} / \mathrm{w}$ in $\mathrm{BaTiO}_{3}$ within: commercial polyester (a), laboratory polyester (b) 
als. Polymer matrix provides the wide peak, while the presence of ceramic particles becomes evident via a number of sharp peaks. The relative intensity of the recorded peaks is representative for the amount of each constituent material in the nanocomposite's composition [29]. It is interesting to note that all recorded reflections, including the one from the amorphous polymers, are shifted to higher values, in the case of the specimens with the laboratory produced polyester compared to the specimens based on the commercial polyester. In particular, the wide peak of the amorphous phase appears, for the commercial polyester at $19.7^{\circ}$, while for the laboratory one at $21.4^{\circ}$. In the literature, values of $2 \theta$ for the amorphous peak of unsaturated polyesters range between 21.2 to $21.4^{\circ}$. The laboratory polyester (MA6AA4) exhibits its peak within this region. The slight deviation of the commercial type should be attributed to the presence of catalysts residues, resulting from the stage of its production. However, the producing company does not provide details upon the synthesis procedure, the type and the amounts of the used chemicals in the relative product sheet, and thus only qualitative comments can be made. Reflections related to $\mathrm{BaTiO}_{3}$ in composites with commercial resin appear at the same values of $2 \theta$ angles with the corresponding of pure barium titanate. On the contrary, all relative XRD peaks in the laboratory polyester based composites are shifted to higher $2 \theta$ values systematically. Specimen with $5 \% \mathrm{w} / \mathrm{w}$ in $\mathrm{BaTiO}_{3}$, displays a peak shift of $0.32^{\circ}$, while specimen with $20 \% \mathrm{w} / \mathrm{w}$ in $\mathrm{BaTiO}_{3}$ displays a $0.16^{\circ}$ peak shift. This behaviour could be related to a distortion of the unit cell because of enhanced hardening (via curing process) in the case of MA6AA4 resin. The unit cell distortion results in lowering the distance of the adjacent planes, and thus in accordance with Bragg law peaks are shifted to higher values.

\subsection{Infra red spectroscopy via Fourier transformation (FT-IR) characterization}

Figure 3, depicts the FT-IR imprint of barium titanate nano-powder. This spectrum can be divided into five characteristic regions. Region i, is the most important peak for barium titanate and corresponds to wavelength range between $530-700 \mathrm{~cm}^{-1}$ (usually between $560-680 \mathrm{~cm}^{-1}$ ). This peak is due to the vibration of the bond between titanium and oxygen (Ti-O bond) [30-33]. Region ii, corresponds to a

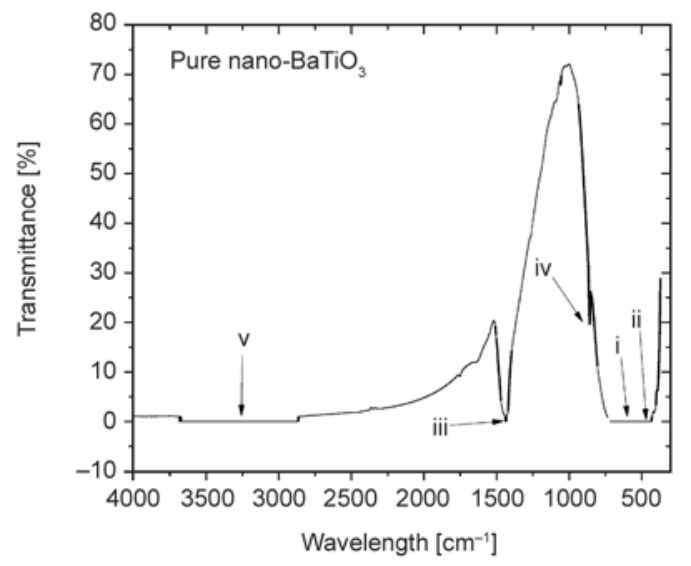

Figure 3. Infra red spectroscopy via Fourier transformation (FT-IR) spectrum from pure $\mathrm{BaTiO}_{3}$ nano-powder at a wavelength range between 4000$200 \mathrm{~cm}^{-1}$

peak at $450 \mathrm{~cm}^{-1}$ approximately, which is caused by vibrations between metal atoms and oxygen (Ti-O and $\mathrm{Ba}-\mathrm{O}$ bonds) $[30,32,34]$. Both previous referred regions are not clearly visible in Figure 3 as from their nature these peaks are difficult to be detected [34]. The formed plateau in the range 993$370 \mathrm{~cm}^{-1}$, indicates their presence instead of a clear separation between the two peaks. The most easily detected region iii, corresponds to a wavelength at $1453 \mathrm{~cm}^{-1}$ and has to do with carbonate ion impurities ( $\mathrm{C}-\mathrm{O}$ bond) [30], which ordinarily came from barium titanate's synthesis. Region iv at $859 \mathrm{~cm}^{-1}$ corresponds to bonds between $\mathrm{Ba}$, $\mathrm{Ti}$ and $\mathrm{O}$. The last region $\mathrm{v}$, corresponds to a large range of bands between $3670-2870 \mathrm{~cm}^{-1}$, which has to do with absorbed moisture from the pellets due to hygroscopic potassium bromide.

The aim of the FT-IR measurements, besides that they are performed for the first time in the specific composite systems, is to examine if the vibration of characteristic bonds of the polymeric matrices is affected by the presence of barium titanate and to what extent. Figures 4 and 5 show the spectra from all the examined composites, while the main peaks of each kind of pure polyester are listed in Table 3. All the basic characteristic peaks related to polyesters according to the literature [23-25, 35-41] are present and detectable in the spectra of both kinds of polyesters. The symbols used for the identification of each peak, can be explained as follows: i) regarding the shape of the peak: (sh) means sharp and (br) means broad, ii) regarding the magnitude of the peak: (s) means strong, (m) means medium, (w) means weak and (pl) means plateau. Table 4 
Table 3. FT-IR spectra characteristic peaks from the two kinds of polyester polymer matrixes

\begin{tabular}{|c|c|c|c|}
\hline \multirow{3}{*}{ Characteristic chemical group } & \multirow{3}{*}{$\begin{array}{l}\text { Wavelength from literature } \\
\qquad\left[\mathrm{cm}^{-1}\right]\end{array}$} & \multirow{2}{*}{\multicolumn{2}{|c|}{$\begin{array}{c}\text { Peak appearance wavelength }\left[\mathrm{cm}^{-1}\right] \\
\text { Composite's polyester polymer matrix }\end{array}$}} \\
\hline & & & \\
\hline & & Commercial polyester & Laboratory MA6AA4 polyester \\
\hline $\begin{array}{c}-\mathbf{O H} \\
\text { vibration stretch }\end{array}$ & $3600-3200$ & $\begin{array}{l}3534 \mathrm{w} / \mathrm{br} \\
3443 \mathrm{w} / \mathrm{br}\end{array}$ & $\begin{array}{l}3540 \mathrm{w} / \mathrm{br} \\
3459 \mathrm{w} / \mathrm{br}\end{array}$ \\
\hline $\begin{array}{c}\mathbf{C}-\mathbf{H} \\
\text { vibration stretch, } \\
\text { styrene's aromatic ring } \\
\end{array}$ & 3024 & $3029 \mathrm{w} / \mathrm{sh}$ & $3029 \mathrm{w} / \mathrm{sh}$ \\
\hline $\begin{array}{c}>\mathbf{C H}_{2},-\mathbf{C H}_{3} \\
\text { vibration stretch, } \\
\text { aliphatic parts }\end{array}$ & $2980-2950$ & $\begin{array}{l}2980 \mathrm{w} / \mathrm{sh} \\
2934 \mathrm{~m} / \mathrm{sh}\end{array}$ & $2958 \mathrm{~m} / \mathrm{sh}$ \\
\hline $\begin{array}{c}>\mathbf{C H}_{2} \\
\text { vibration stretch, } \\
\text { circular and linear parts }\end{array}$ & $2890-2850$ & $2980 \mathrm{w} / \mathrm{sh}$ & $2878 \mathrm{w} / \mathrm{sh}$ \\
\hline $\begin{array}{c}>\mathbf{C}=\mathbf{O} \\
\text { vibration stretch }\end{array}$ & $1736-1726$ & $1731 \mathrm{~s} / \mathrm{sh}$ & $1736 \mathrm{~s} / \mathrm{sh}$ \\
\hline $\begin{array}{c}\mathbf{C}=\mathbf{C} \\
\text { vibration stretch within } \\
\text { the aromatic ring }\end{array}$ & $\begin{array}{l}1600 \\
1580 \\
1500\end{array}$ & $\begin{array}{l}1600 \mathrm{~m} / \mathrm{sh} \\
1581 \mathrm{~m} / \mathrm{sh} \\
1494 \mathrm{~m} / \mathrm{sh}\end{array}$ & $\begin{array}{c}1603 \mathrm{w} / \mathrm{sh} \\
- \\
1495 \mathrm{w} / \mathrm{sh}\end{array}$ \\
\hline $\begin{array}{l}\mathbf{C}-\mathbf{C} \\
\text { vibration stretch within } \\
\text { the aromatic ring }\end{array}$ & $1480-1400$ & $1453 \mathrm{~s} / \mathrm{sh}$ & $1456 \mathrm{~m} / \mathrm{sh}$ \\
\hline $\begin{array}{c}\mathbf{C H}_{3} \\
\text { symmetric bending vibration }\end{array}$ & $1390-1370$ & $1381 \mathrm{w} / \mathrm{sh}$ & $1393 \mathrm{~m} / \mathrm{sh}$ \\
\hline $\begin{array}{c}\mathbf{C}_{\mathrm{sp} 3}-\mathbf{O} \\
\text { (ester bond) }\end{array}$ & $1330-1200$ & $1283 \mathrm{~s} / \mathrm{br}$ & $1250 \mathrm{w} / \mathrm{br}$ \\
\hline $\begin{array}{c}\mathbf{C}_{\mathbf{s p 3}-\mathbf{O}} \\
\text { (alcohol bond) }\end{array}$ & $1200-1100$ & $1122 \mathrm{~m} / \mathrm{br}$ & $1162 \mathrm{~m} / \mathrm{sh}$ \\
\hline $\begin{array}{c}\mathbf{C}-\mathbf{H} \\
\text { «in plane» } \\
\text { vibrations } \\
\end{array}$ & $1080-1036$ & $1068 \mathrm{~m} / \mathrm{sh}$ & $1077 \mathrm{~m} / \mathrm{br}$ \\
\hline $\begin{array}{c}\mathbf{C}=\mathbf{C} \\
\text { unsaturated polyester's double bond }\end{array}$ & 982 & $990 \mathrm{w} / \mathrm{br}$ & $978 \mathrm{w} / \mathrm{sh}$ \\
\hline $\begin{array}{c}\mathbf{C}=\mathbf{C} \\
\text { styrene's double bond }\end{array}$ & 912 & $913 \mathrm{w} / \mathrm{br}$ & - \\
\hline $\begin{array}{c}\mathbf{C}-\mathbf{H} \\
\text { deformation vibration } \\
\text { «out of plane» } \\
1 \text { or } 2 \text { neighbour } \mathrm{H} \text { of benzene ring }\end{array}$ & $876-815$ & $847 \mathrm{~m} / \mathrm{br}$ & $\begin{array}{l}877 \mathrm{w} / \mathrm{sh} \\
814 \mathrm{w} / \mathrm{br}\end{array}$ \\
\hline $\begin{array}{c}\mathbf{C}-\mathbf{H} \\
\text { deformation vibration } \\
\text { «out of plane» } \\
3 \text { or } 4 \text { neighbour } \mathrm{H} \text { of benzene ring }\end{array}$ & 750 & $745 \mathrm{~s} / \mathrm{sh}$ & $764 \mathrm{~m} / \mathrm{sh}$ \\
\hline $\begin{array}{c}\mathbf{C}-\mathbf{H} \\
\text { deformation vibration } \\
\text { «out of plane» } \\
5 \text { neighbour H of benzene ring }\end{array}$ & $\begin{array}{l}700 \\
666\end{array}$ & $\begin{array}{l}700 \mathrm{~s} / \mathrm{sh} \\
649 \mathrm{w} / \mathrm{br}\end{array}$ & $703 \mathrm{~s} / \mathrm{sh}$ \\
\hline
\end{tabular}

lists peaks and vibrational modes of pure $\mathrm{BaTiO}_{3}$ and of $\mathrm{BaTiO}_{3} /$ nanocomposites. It is easily noticeable, a difference in the characteristics of each peak. This difference is attributed to the increase of the proportion of $\mathrm{BaTiO}_{3}$ in the specimens, thus a variation in the intensity of each peak occurs.

Finally, there are two important remarks that must be noted. The first one is that there is a specific region in the FTIR spectra that is characteristic for each specimen relative to its' content in barium titanate compared to the intensity of a certain peak. For the specimens with commercial polyester, this specific region is located between $458-431 \mathrm{~cm}^{-1}$, while in specimens with laboratory polyester this region is located between $432-428 \mathrm{~cm}^{-1}$. The second one is that independently from barium titanate's content in each specimen, all the recorded peaks remain in the same values of wavelength, in contrast to similar composite systems [42]. 

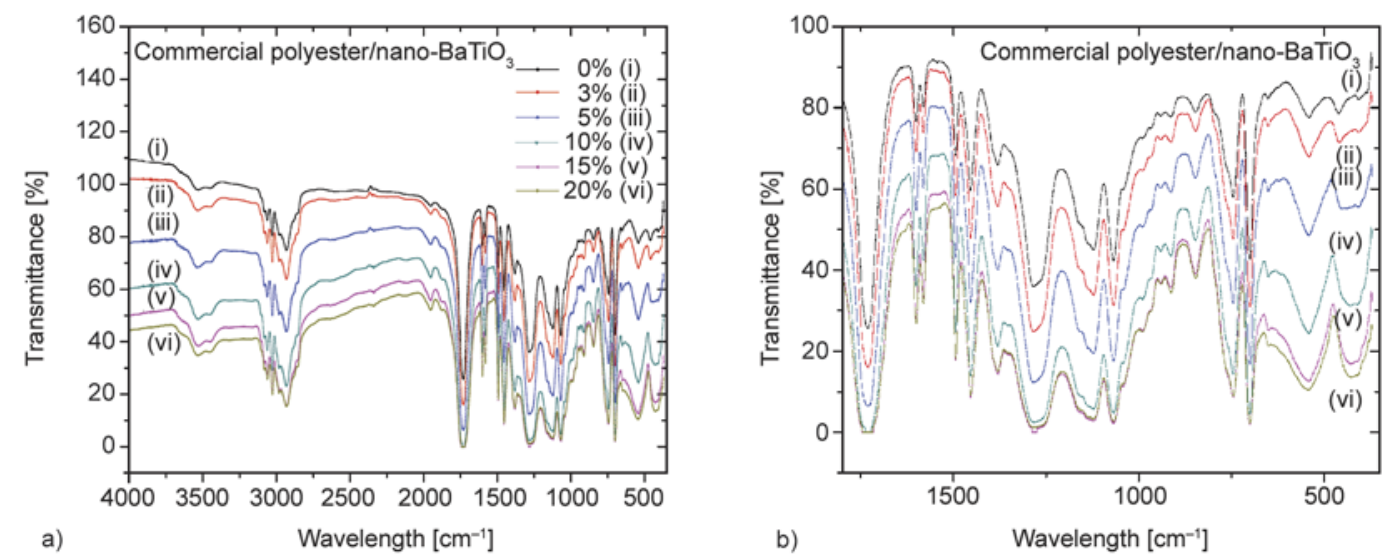

Figure 4. Infra red spectroscopy via Fourier transformation (FT-IR) spectra from specimens with $0-20 \% \mathrm{w} / \mathrm{w}$ content in $\mathrm{BaTiO}_{3}$ nano-particles within commercial polyester at a wavelength range between: $4000-200 \mathrm{~cm}^{-1}$ (a) and $1800-350 \mathrm{~cm}^{-1}$ (b)
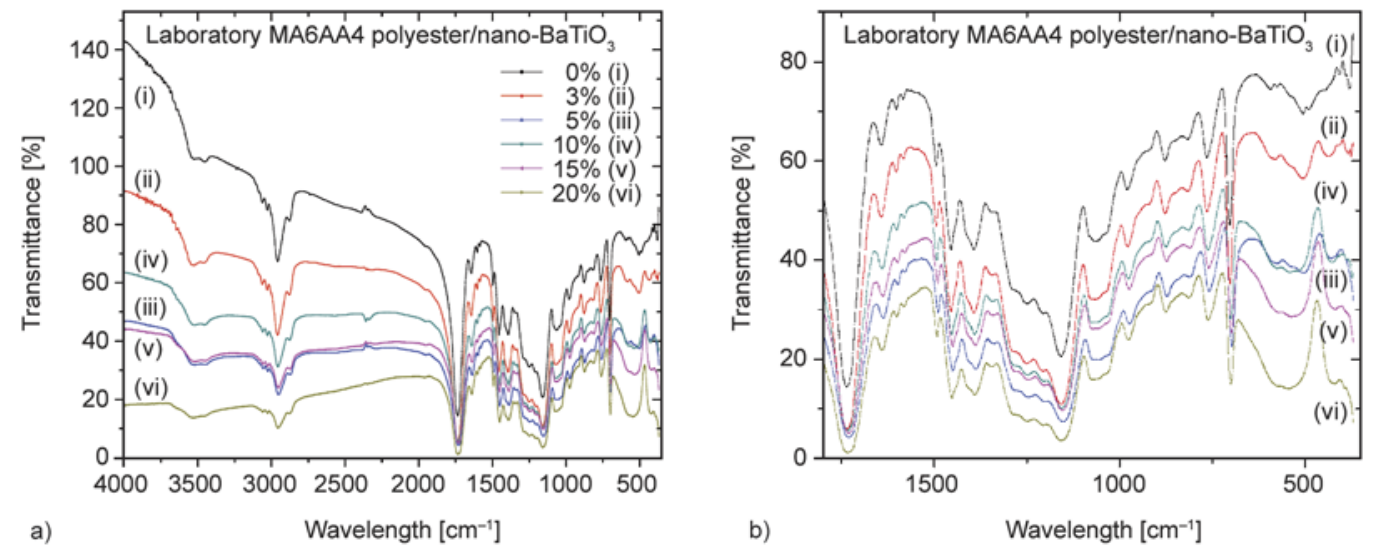

Figure 5. Infra red spectroscopy via Fourier transformation (FT-IR)) spectra from specimens with $0-20 \%$ w/w content in $\mathrm{BaTiO}_{3}$ nano-particles within laboratory MA6AA4 polyester at a wavelength range between: $4000-200 \mathrm{~cm}^{-1}$ (a) and $1800-350 \mathrm{~cm}^{-1}$ (b)

Table 4. FT-IR spectra characteristic peaks from pure $\mathrm{BaTiO}_{3}$ nano-powder and all kind of developed composites with either commercial or laboratory polyester polymer matrix

\begin{tabular}{|c|c|c|c|c|}
\hline \multirow{3}{*}{$\begin{array}{l}\text { Characteristic } \\
\text { chemical group }\end{array}$} & \multirow{3}{*}{$\begin{array}{c}\text { Wavelength from } \\
\text { literature } \\
{\left[\mathrm{cm}^{-1}\right]}\end{array}$} & \multicolumn{3}{|c|}{ Peak appearance wavelength $\left[\mathrm{cm}^{-1}\right]$} \\
\hline & & \multirow{2}{*}{ pure $\mathrm{BaTiO}_{3}$} & \multicolumn{2}{|c|}{ Composite's polyester polymer matrix } \\
\hline & & & Commercial polyester & Laboratory MA6AA4 polyester \\
\hline $\begin{array}{c}\text { Ba-O, } \mathbf{T i}-\mathbf{O} \\
\text { vibration stretch }\end{array}$ & $405-450 \mathrm{~m} / \mathrm{sh}$ & $432-727 \mathrm{pl}$ & $\begin{array}{l}458 \mathrm{w} / \mathrm{br}\left(3,5 \% \mathrm{w} / \mathrm{w} \mathrm{BaTiO}_{3}\right) \\
431 \mathrm{~m} / \mathrm{br}\left(10-20 \% \mathrm{w} / \mathrm{waTiO}_{3}\right)\end{array}$ & $\begin{array}{l}432 \mathrm{w} / \mathrm{br}\left(3,5 \% \mathrm{w} / \mathrm{w} \mathrm{BaTiO}_{3}\right) \\
428 \mathrm{~m} / \mathrm{br}\left(10-20 \% \mathrm{w} / \mathrm{w} \mathrm{BaTiO}_{3}\right)\end{array}$ \\
\hline $\begin{array}{c}\text { Ti-O } \\
\text { vibration stretch }\end{array}$ & $530-700 \mathrm{~s} / \mathrm{sh}$ & $432-727 \mathrm{pl}$ & $\begin{array}{l}\left.541 \mathrm{w} / \mathrm{br}(3,5 \% \mathrm{w} / \mathrm{w} \mathrm{BaTiO})_{3}\right) \\
541 \mathrm{~m} / \mathrm{br}(10-20 \% \mathrm{w} / \mathrm{w} \mathrm{BaTiO} 3)\end{array}$ & $\begin{array}{l}504 \mathrm{w} / \mathrm{br}\left(3,5 \% \mathrm{w} / \mathrm{w} \mathrm{BaTiO}_{3}\right) \\
504 \mathrm{~m} / \mathrm{br}\left(10-20 \% \mathrm{w} / \mathrm{w} \mathrm{BaTiO}_{3}\right)\end{array}$ \\
\hline $\begin{array}{l}\text { Ba-O, } \mathbf{T i}-\mathbf{O} \\
\text { vibration stretch }\end{array}$ & $852-860 \mathrm{w} / \mathrm{sh}$ & $857 \mathrm{w} / \mathrm{sh}$ & $\begin{array}{l}847 \mathrm{w} / \mathrm{sh}\left(3 \% \mathrm{w} / \mathrm{w} \mathrm{BaTiO}_{3}\right) \\
847 \mathrm{~m} / \mathrm{sh}\left(5-20 \% \mathrm{w} / \mathrm{w} \mathrm{BaTiO}_{3}\right)\end{array}$ & 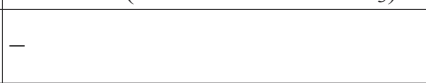 \\
\hline $\begin{array}{c}\text { C-O } \\
\text { vibration stretch }\end{array}$ & $1440-1444 \mathrm{~m} / \mathrm{sh}$ & $1433 \mathrm{~m} / \mathrm{sh}$ & $1453 \mathrm{~s} / \mathrm{sh}(3-20 \% \mathrm{w} / \mathrm{w}$ BaTiO3) & $\begin{array}{l}1455 \mathrm{~m} / \mathrm{sh}\left(3 \% \mathrm{w} / \mathrm{w} \mathrm{BaTiO}_{3}\right) \\
1450 \mathrm{w} / \mathrm{sh}\left(5 \% \mathrm{w} / \mathrm{w} \mathrm{BaTiO}_{3}\right) \\
1453 \mathrm{w} / \mathrm{sh}\left(10 \% \mathrm{w} / \mathrm{waTiO}_{3}\right) \\
1451 \mathrm{w} / \mathrm{sh}\left(15 \% \mathrm{w} / \mathrm{w} \mathrm{BaTiO}_{3}\right) \\
1452 \mathrm{w} / \mathrm{sh}\left(20 \% \mathrm{w} / \mathrm{w} \mathrm{BaTiO}_{3}\right)\end{array}$ \\
\hline $\begin{array}{c}-\mathbf{O H} \\
\text { vibration stretch }\end{array}$ & $3389-3433 \mathrm{~m} / \mathrm{br}$ & $2866-3674 \mathrm{pl}$ & - & 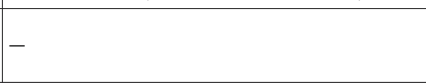 \\
\hline
\end{tabular}

\subsection{Thermal characterization}

Glass transition temperature $\left(T_{\mathrm{g}}\right)$ of pure commercial polyester resin was found to be $57^{\circ} \mathrm{C}$, while $T_{\mathrm{g}}$ of pure laboratory MA6AA4 polyester resin was found to be $45^{\circ} \mathrm{C}$. The $T_{\mathrm{g}}$ of all the other examined systems are shown in Figure 6. The main tendency for the nanocomposites of both polyester polymer matrices is the reduction of $T_{\mathrm{g}}$ with the increase of 
$\mathrm{BaTiO}_{3}$ content. Variation of $T_{\mathrm{g}}$ with filler content in polymer matrix micro- or nanocomposites has been observed and reported previously [43]. Variation has been attributed to the type of the occurring interactions (strong or weak) between the reinforcing particles surface and the macromolecular chains, as well as to the level of adhesion of the filler by the matrix. Lowering of $T_{\mathrm{g}}$ implies weak interactions and poor adhesion between filler and polymer matrix. If the macromolecules are not anchored on the particles surface, their co-operative movement is facilitated and thus less thermal energy should be provided to the system in order to relax simultaneously. The latter becomes evident with a systematic reduction of $T_{\mathrm{g}}$ with ceramic filler content. The impact of glass transition temperature leveling of on the composites' performance, results in narrowing the temperature range where the materials can serve appropriately. Figure 6 depicts this behaviour, points represent the mean value between the upper and lower limit of the glass transition range [44]. It is interesting to note that the diminishing rate of $T_{\mathrm{g}}$ with the $\mathrm{BaTiO}_{3}$ content, as expressed by the slope of the average values from Figure 6, varies with the type of the polymer matrix. Slope for composites with commercial polyester is equal to $-3.63^{\circ} \mathrm{C} / \% \mathrm{w} / \mathrm{w}$ $\mathrm{BaTiO}_{3}$ content, while slope for laboratory polyester is equal to $-0.54^{\circ} \mathrm{C} / \% \mathrm{w} / \mathrm{w} \mathrm{BaTiO}_{3}$ content. This difference, by an order of magnitude, can be considered as a clear indication for the quality of the produced nanocomposites and the achieved dispersion of ceramic particles within the employed polyesters. Laboratory produced polyester appears to be more suitable for the preparation of nanocomposites and the adhesion between matrix and filler is enhanced in this case. It should be noted that

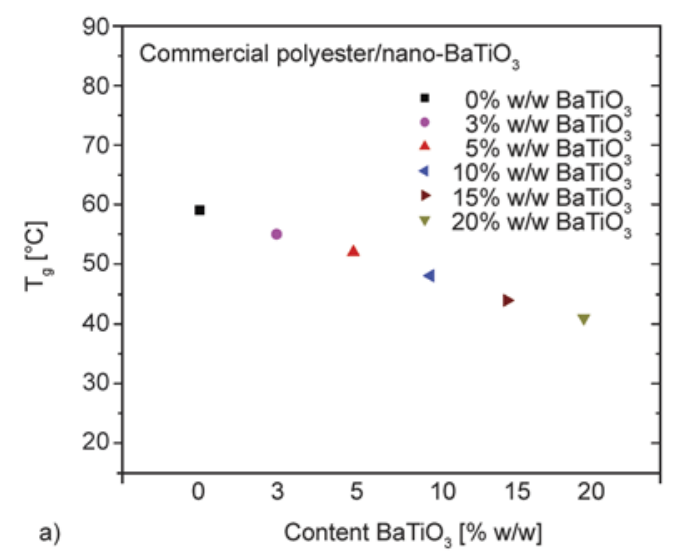

morphological investigation via SEM previously mentioned, lead to the same conclusion.

\subsection{Mechanical characterization}

The results of shear and bending tests, for all the examined specimens, are shown in Tables 5 and 6 . It is clear that shear strength values decreases as $\mathrm{BaTiO}_{3}$ content increases. This behaviour is consistent with the DSC results (diminishing of $T_{\mathrm{g}}$ point), so the fact that the adhesion between polyester polymer matrix and nano-particles hinders with the increase in $\mathrm{BaTiO}_{3}$ content is further confirmed. The same behaviour occurs in the specimens with laboratory polyester as polymer matrix, but in this case in a smoother way. As it can be seen maximum shear strength values, for all the nanocomposite systems, are quite close. Another important remark is that shear strength values, for specimens with commercial polyester are approximately two times higher than the corresponding values for specimens with laboratory polyester. Maximum bending strength values are approximately ten times higher than the corresponding shear strength values for composites with commercial polyester. These differences between both types of polyesters are in accordance with the brittle performance of the commercial one. Concerning the bending tests for specimens with laboratory polyester, should be noted that all samples demonstrated an elastomeric behaviour being thus unable to reach fracture. This qualitative modification, in the mechanical performance, between the two types of the employed polyesters can be considered responsible for the observed differences via SEM and DSC tests in the two sets of nanocomposites. The elastomeric performance of laboratory polyester based nanoscomposites is shown in Figure 7. The occur-

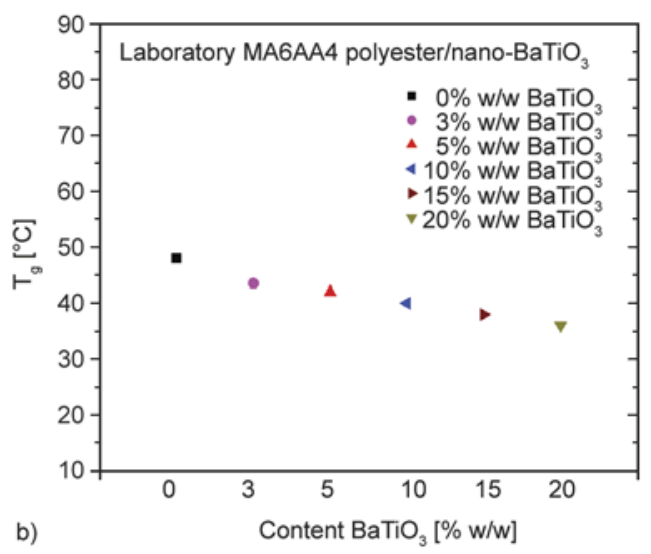

Figure 6. $T_{\mathrm{g}}$ values for each specimen versus \% content in $\mathrm{BaTiO}_{3}$ nano-particles with: commercial polyester (a) and laboratory MA6AA4 polyester polymer matrix (b) 
Table 5. Deflection, maximum applied force, shear strength and error range of shear strength values for shear tests

\begin{tabular}{|c|c|c|c|c|c|}
\hline $\begin{array}{l}\text { Kind of polyester } \\
\text { polymer matrix }\end{array}$ & $\begin{array}{c}\text { Specimen's content } \\
\text { in } \mathrm{BaTiO}_{3} \\
{[\% \mathrm{w} / \mathrm{w}]}\end{array}$ & $\begin{array}{l}\text { Diflection, } x \\
{[\mu \mathrm{m}]}\end{array}$ & $\begin{array}{c}\text { Maximum applied } \\
\text { force, } \mathbf{P}_{\max } \\
{[\mathbf{N}]}\end{array}$ & $\begin{array}{c}\text { Shear strength, } \tau_{\mathrm{b}} \\
{[\mathrm{MPa}]}\end{array}$ & $\begin{array}{c}\text { Shear's strength } \\
\text { error range } \\
\pm[\mathrm{MPa}] \\
\end{array}$ \\
\hline \multirow{6}{*}{$\begin{array}{l}\text { Specimens with } \\
\text { commercial } \\
\text { polyester/BaTiO }\end{array}$} & 0 & 15.2 & 244.4 & 3.90 & 0.3 \\
\hline & 3 & 14.2 & 228.3 & 3.65 & 0.3 \\
\hline & 5 & 10.8 & 173.6 & 2.80 & 0.2 \\
\hline & 10 & 8.8 & 141.5 & 2.25 & 0.2 \\
\hline & 15 & 8.2 & 131.8 & 2.10 & 0.2 \\
\hline & 20 & 7.8 & 125.4 & 2.00 & 0.1 \\
\hline \multirow{6}{*}{$\begin{array}{l}\text { Specimens with } \\
\text { laboratory } \\
\text { MA6AA4 } \\
\text { polyester/BaTiO }\end{array}$} & 0 & 7.8 & 125.4 & 2.00 & 0.1 \\
\hline & 3 & 7.0 & 112.5 & 1.80 & 0.1 \\
\hline & 5 & 7.2 & 115.8 & 1.85 & 0.1 \\
\hline & 10 & 6.8 & 109.3 & 1.75 & 0.1 \\
\hline & 15 & 6.7 & 107.7 & 1.70 & 0.1 \\
\hline & 20 & 6.2 & 99.7 & 1.60 & 0.1 \\
\hline
\end{tabular}

Table 6. Deflection, maximum applied force, bending strength and error range of bending strength values for bending tests

\begin{tabular}{|l|c|c|c|c|c|}
\hline $\begin{array}{c}\text { Kind of polyester } \\
\text { polymer matrix }\end{array}$ & $\begin{array}{c}\text { Specimen's content } \\
\text { in } \mathbf{B a T i O}_{\mathbf{3}} \\
{[\mathbf{\%} \mathbf{w} / \mathbf{w}]}\end{array}$ & $\begin{array}{c}\text { Diflection, } \mathbf{x} \\
{[\boldsymbol{\mu \mathbf { m } ]}}\end{array}$ & $\begin{array}{c}\text { Maximum applied } \\
\text { force, } \mathbf{P}_{\mathbf{m a x}} \\
{[\mathbf{N}]}\end{array}$ & $\begin{array}{c}\text { Bending strength, } \\
\mathbf{\sigma}_{\mathbf{b}} \\
{[\mathbf{M P a}]}\end{array}$ & $\begin{array}{c}\text { Bending's strength } \\
\text { error range } \\
\pm[\mathbf{M P a}]\end{array}$ \\
\hline \multirow{4}{*}{$\begin{array}{l}\text { Specimens with } \\
\text { commercial poly- }\end{array}$} & 0 & 1.2 & 19.3 & 33.75 & 2.4 \\
\cline { 2 - 6 } ester/ $\mathrm{BaTiO}_{3}$ & 3 & 1.1 & 17.7 & 30.95 & 2.2 \\
\cline { 2 - 6 } & 5 & 0.9 & 14.5 & 25.30 & 1.8 \\
\cline { 2 - 6 } & 10 & 0.9 & 14.5 & 25.30 & 1.8 \\
\cline { 2 - 6 } & 20 & 0.8 & 12.9 & 22.50 & 1.6 \\
\hline
\end{tabular}

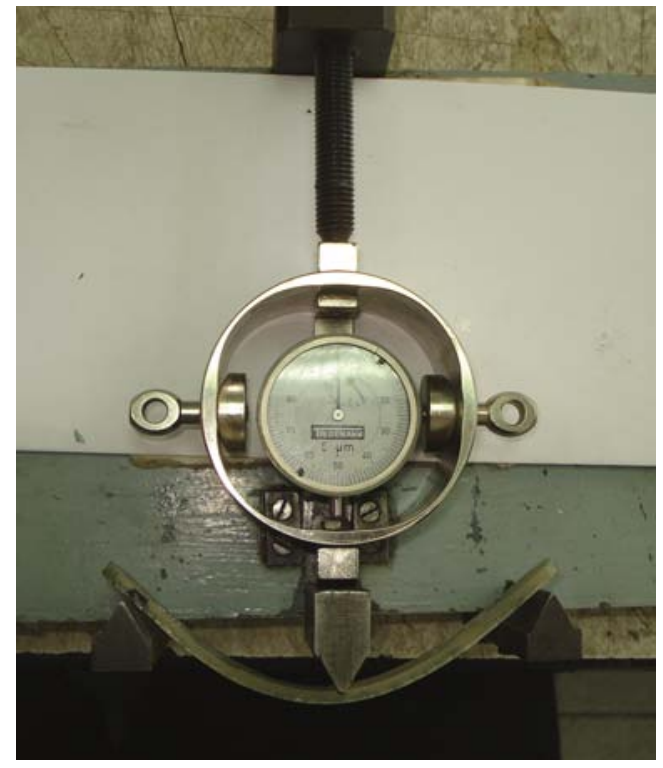

Figure 7. Snapshot showing the elastomer nature of composites with laboratory polymer matrix during bending tests

ring elastomeric performance is ascribed to the structure of the MA6AA4 laboratory polyester. During its synthesis the concentrations of acid raw materi- als are the following: $60 \%$ maleic acid and $40 \%$ adipic acid. Thus the elastomeric behaviour of the nanocomposites - with the laboratory polymer matrix - is attributed to the high percentage of adipic acid in the final thermosetting unsaturated polyester structure. Adipic acid has a linear structure without any ramifications; therefore the polymer chain acquires mobility. Macroscopically, enhanced polymers' chain mobility is translated to elastomeric mechanical behaviour.

\subsection{Broadband dielectric spectroscopy (BDS) characterization}

Dielectric data were firstly expressed in terms of dielectric permittivity and then transformed via Equation (1) in terms of electric modulus. Electric modulus is considered as an effective formalism for the investigation of dielectric data, since it eliminates the parasitic and undesirable effect of electrode polarization [45-47]. Electric modulus is defined as the inverse quantity of complex permittivity, as shown in Equation (1):

$$
M^{*}=\frac{1}{\varepsilon^{*}}=\frac{1}{\varepsilon^{\prime}-j \varepsilon^{\prime \prime}}=\frac{\varepsilon^{\prime}}{\varepsilon^{\prime 2}+\varepsilon^{\prime 2}}+j \frac{\varepsilon^{\prime \prime}}{\varepsilon^{\prime 2}+\varepsilon^{\prime 2}}=M^{\prime}+j M^{\prime \prime}
$$



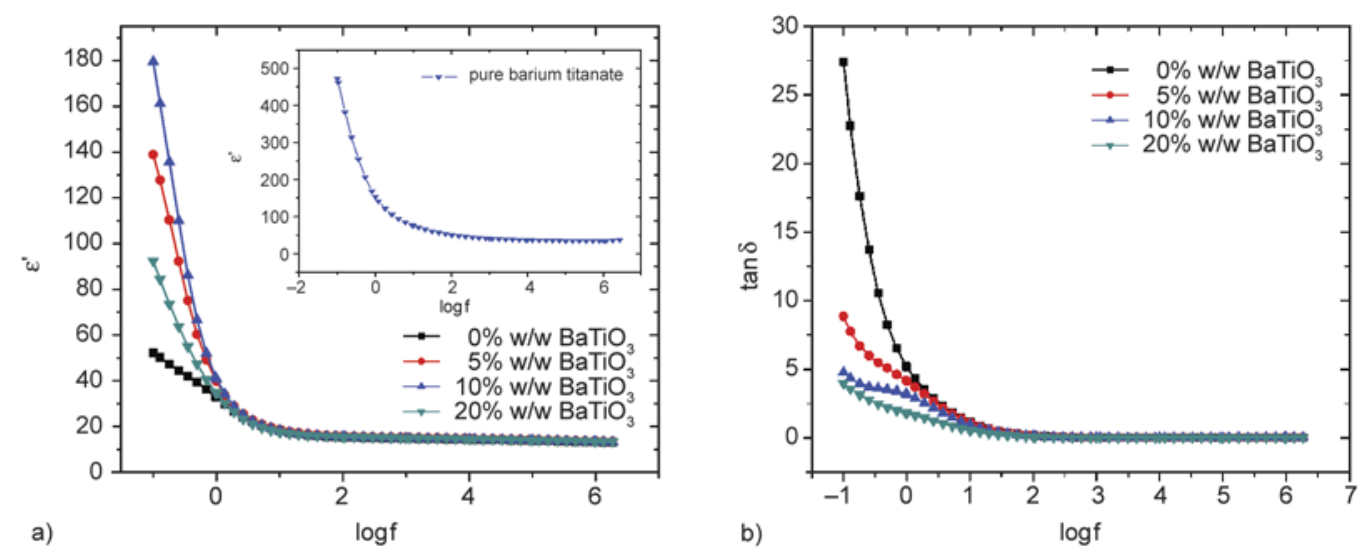

Figure 8. Real part of dielectric permttivity (a), and $\tan \delta(b)$ as a function of frequency for the laboratory based systems, at $50^{\circ} \mathrm{C}$. Inset depicts the variation of $\left(\varepsilon^{\prime}\right)$ versus $\log$, at $50^{\circ} \mathrm{C}$, for pure barium titanate

where $\varepsilon^{\prime}, M^{\prime}$ and $\varepsilon^{\prime \prime}, M^{\prime \prime}$ are the real and the imaginary parts of dielectric permittivity and electric modulus respectively.

The variation of the real part of dielectric permittivity as a function of frequency, at $50^{\circ} \mathrm{C}$, for all the laboratory polyester (MA6AA4) based systems is shown in Figure $8 \mathrm{a}$, while inset presents $\left(\varepsilon^{\prime}\right)$ as a function of frequency, at the same temperature, for pure barium titanate. In all cases $\left(\varepsilon^{\prime}\right)$ diminishes with frequency reflecting the decrease of polarization due to the inertia of the dipoles to follow the alternation of the applied field. Permittivity alters with filler content, but this increase appears not be systematic indicating that the optimum performance does not correspond to the maximum barium titanate content. This point is further discussed later. The variation of loss tangent for the same systems is given in Figure 8b. Loss tangent acquires high values in the low frequency range, and curves are shifted to lower frequencies as the ceramic filler content increases. Recorded behaviour is ascribed to interfacial polarization [45-47], although the

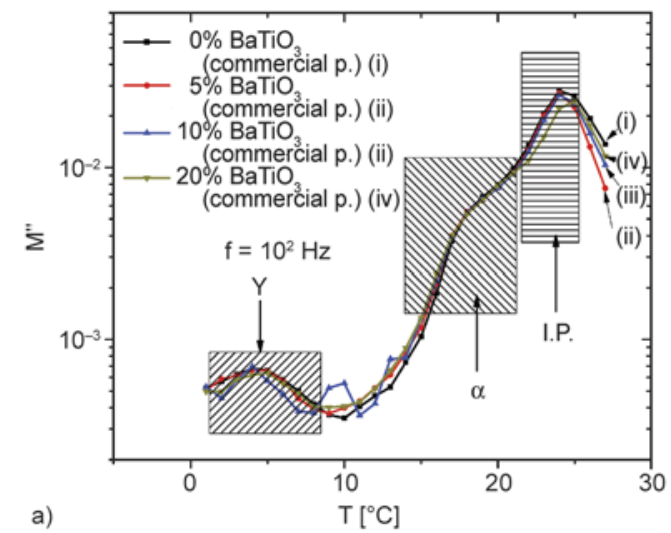

high values of losses could be, possibly, influenced by electrode polarization. Analogous behaviour has been found for the commercial polyester based systems.

Figure 9 depicts the loss modulus index versus temperature spectra of all the examined systems, at $10^{2} \mathrm{~Hz}$, where all the recorded relaxation phenomena are present. Three relaxation processes are evident in the spectra of commercial polyester based systems in Figure 9a, while four relaxations are detected in the spectra of the MA6AA4 polyester based nanocomposites in Figure $9 \mathrm{~b}$. In the second case, the two faster mechanisms, namely $\gamma$ - and $\beta$ mode, are recorded in the range from 2 to $7^{\circ} \mathrm{C}$ and 9 to $13^{\circ} \mathrm{C}$, respectively. These modes are characterized by short relaxation times and are assigned to local motions or re-arrangements of small polymer parts. In particular, $\gamma$-mode is attributed to the motion of small parts of the main polymer chain, such as hydrogen and phenyl's aromatic ring, which are connected with carbon atoms of the main polymer chain with single bonds. Further, $\beta$-mode is related

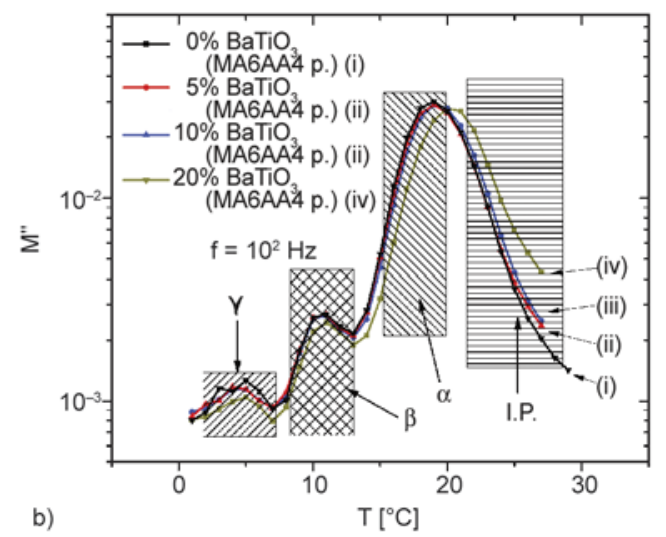

Figure 9. Imaginary part of electric modulus versus temperature at $10^{2} \mathrm{~Hz}$, for specimens with commercial polyester (a) and laboratory MA6AA4 polyester (b) 
to the re-arrangement of polar side groups, which in our case are oxygen atoms connected with carbon atoms of the main polymer chain via double bonds. Glass to rubber transition of the matrix gives rise to a slower relaxation process ( $\alpha$-mode), recorded in the vicinity of $18^{\circ} \mathrm{C}$. The difference between the determined values of $T_{\mathrm{g}}$ via DSC and BDS should be assigned to the dynamic nature of the glass to rubber transition effect. BDS reflects better the dynamic nature of the process and thus the determined value of $T_{\mathrm{g}}$ depends on the frequency of the applied electrical field. However, the peak depicted in Figure $9 \mathrm{~b}$ is broad covering a range of almost $15^{\circ} \mathrm{C}$, from its onset at $13^{\circ} \mathrm{C}$ approximately to its end point close to $28^{\circ} \mathrm{C}$. This wide and intense peak is attributed to the superposition of two relaxation processes, that is $\alpha$-mode $\left(13-21^{\circ} \mathrm{C}\right)$ and Interfacial Polarization (IP) $\left(22-28^{\circ} \mathrm{C}\right)$. IP appears in heterogeneous systems because of the accumulation of non-bonded charges at the interface between the constituents of the system, where they form large dipoles. The inertia of these dipoles to follow the alternation of the applied field is the origin of the IP relaxation process [45-49], which is the slowest recorded effect. In general, IP is strengthened with the increase of the reinforcing phase and its relaxation time is enhanced. The small shift of the loss peak to higher temperatures in the case of the specimen with the maximum filler content is in accordance with the previous remark. Figure 9a presents the loss modulus spectra versus temperature for the systems with the commercially available polyester. The general trend of the recorded response is similar to that of the MA6AA4 polyester based systems. However, differences between Figure 9a and 9b reflect varia-

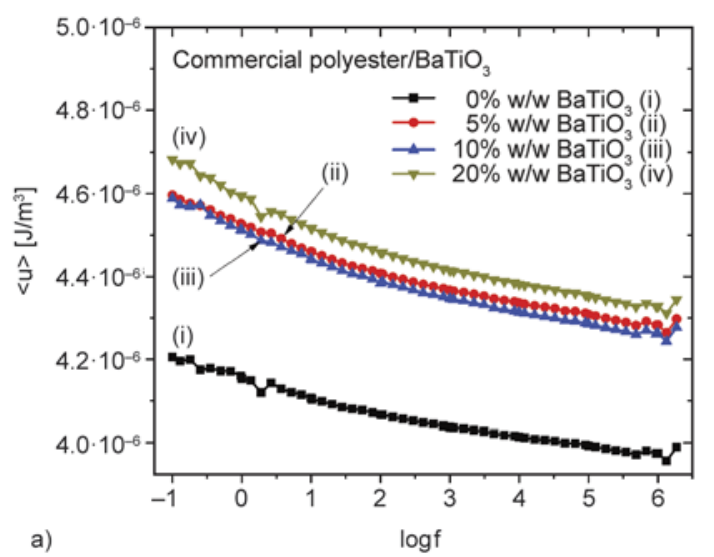

tions in the systems' structure. In the commercial polyester spectra $\alpha$-mode and IP are recorded distinctly. $\alpha$-mode's peak $\left(14-22^{\circ} \mathrm{C}\right)$ is present as a 'hump' on the ascending curve, while IP is clearly recorded at higher temperature $\left(23-26^{\circ} \mathrm{C}\right)$. The variation of dynamics (peak shift rate with temperature) of both processes from the laboratory to the commercial polyester is responsible for the separation of the effects in Figure 9a. Further, the peak corresponding to $\beta$-mode is absent in the spectra of the commercial polyester. Although the accurate chemical structure of the commercial polyester is not given, the absence of $\beta$-mode is indicative for the absence of polar side groups in its main polymer chain or at least for the limited presence of such groups. $\gamma$-mode's peak is located in the vicinity of $2-8^{\circ} \mathrm{C}$ for both types of polyesters. Recorded relaxations in Figure 9a, 9b slightly differ with barium titanate content indicating that the dissipation of energy upon each charging cycle does not vary significantly with filler loading.

Figures 10 and 11 present the density of energy for all the examined systems with respect to commercial (a) and laboratory (b) polyester, as a function of the applied frequency (Figure 10) or temperature (Figure 11). The density of energy has been calculated via Equation (2):

$$
<u>=\frac{1}{2} \cdot \varepsilon_{0} \cdot \varepsilon^{\prime} \cdot\left(\frac{V_{0}}{d}\right)^{2}
$$

where $\varepsilon_{0}$ is the dielectric permittivity of vacuum, $\varepsilon^{\prime}$ the real part of dielectric permittivity of the corresponding specimen, $V_{0}$ is the applied voltage amplitude, which in our case was kept constant at 1 Volt, and $d$ is the specimen's thickness, being equal to

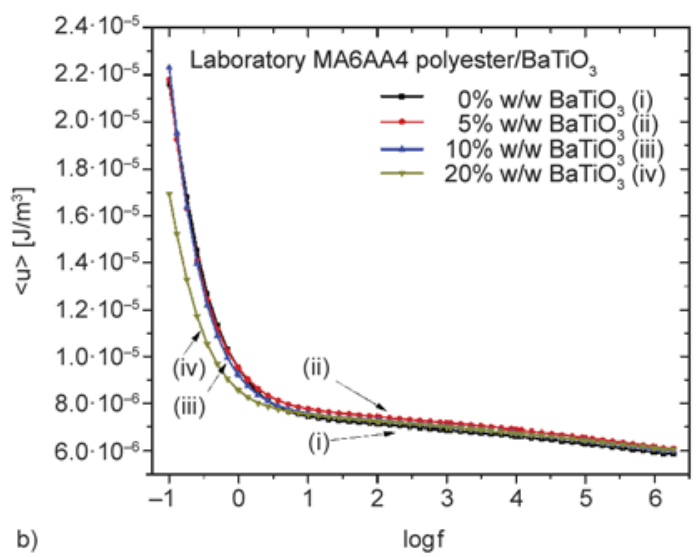

Figure 10. Energy density as a function of frequency for nanocomposites with $0,5,10$ and $20 \% \mathrm{w} / \mathrm{w} \mathrm{BaTiO}_{3}$ embedded in: commercial polyester (a), laboratory MA6AA4 (b) polyester as polymer matrix at $30^{\circ} \mathrm{C}$ 

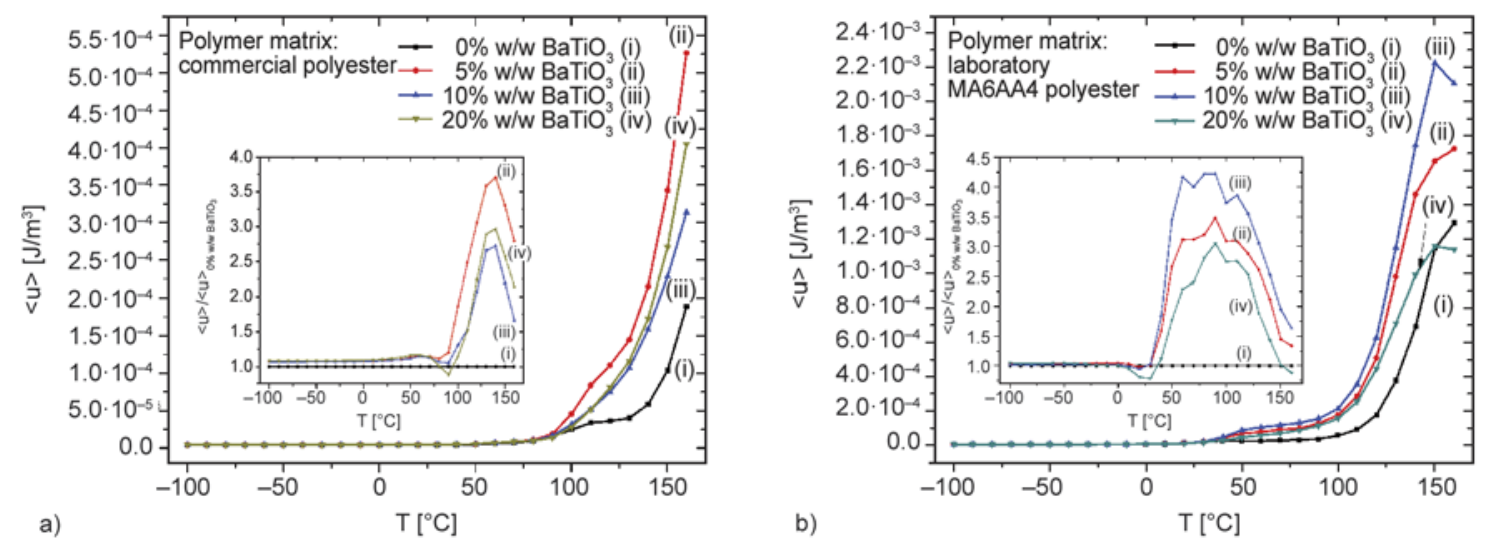

Figure 11. Energy density and normalized energy density versus temperature for nanocomposites with $0,5,10$ and $20 \% \mathrm{w} / \mathrm{w} \mathrm{BaTiO}_{3}$ embedded in: commercial polyester (a), laboratory MA6AA4 (b) polyester as polymer matrix at $10^{-1} \mathrm{~Hz}$

$3 \mathrm{~mm}$. Energy density is a parameter reflecting the storage capability of each nanosystem [50]. From Figure 10 becomes evident that, at constant temperature $30^{\circ} \mathrm{C}$, and in the case of the commercial polyester based systems, the specimen with $20 \% \mathrm{w} / \mathrm{w}$ in $\mathrm{BaTiO}_{3}$ exhibits the highest energy storing capability, while in the case of the laboratory polyester based systems highest energy storage is exhibited by the $10 \% \mathrm{w} / \mathrm{w}$ specimen. Further, energy density values for the laboratory based systems appear to be higher by almost an order of magnitude when compared to the values of the commercial polyester matrix systems.

On the other hand, Figure 11, indicates that the highest energy storage capability due to $\mathrm{BaTiO}_{3}$, is displayed by the specimen with $5 \% \mathrm{w} / \mathrm{w} \mathrm{BaTiO}_{3}$ (commercial polyester) and by the specimen with $10 \% \mathrm{w} / \mathrm{w} \mathrm{BaTiO}_{3}(\mathrm{MA} 6 \mathrm{AA} 4$ polyester). Insets in Figure $11 \mathrm{a}$ and $11 \mathrm{~b}$ depicts the normalized energy density of both sets of nanosystems, with respect to the pure polymer specimen. In accordance with previous comments, the energy storing capability is stronger in the laboratory polyester based nanosystems. From Figures 10 and 11 is evident that the optimum dielectric performance and/or energy storing efficiency, although is related to the ceramic filler content, does not correspond to the maximum loaded contents of barium titanate nanoparticles. It is apparent from Equation (2) that the only material property related to the density of energy is the real part of dielectric permittivity. At constant field's value, well below the material's dielectric strength, and at constant specimens' thickness, the variation of energy density reflects the variation of $\left(\varepsilon^{\prime}\right)$. The latter is influenced by the amount of the employed barium titanate, the temperature, the frequency of the field, and the quality of dispersion of the $\mathrm{BaTiO}_{3}$ nano-particles. It is well known and documented [51-53] that at low frequencies and high temperatures permittivity attains high values because sufficient time and mobility is given to permanent and induced dipoles to be oriented parallel to the applied field. Moreover, increasing the filler content results in higher values of permittivity, since $\left(\varepsilon^{\prime}\right)$ of $\mathrm{BaTiO}_{3}$ is much higher than that of the matrix. However, permittivity does not increase monotonically with filler content, as expected, because the quality of the achieved dispersion of the nano-particles diminishes at high $\mathrm{BaTiO}_{3}$ loadings. Nano-particles tend to form clusters and agglomerates and the samples' preparation is significantly hampered. The presence of agglomerates, the weak adhesion between particles and matrix, and the possible formation of small voids lead to lower permittivity values for the nanocomposites with high barium titanate content. Therefore, the corresponding energy density values decrease. Finally, the formed peaks in the insets of Figure 11 are related to the recorded dielectric relaxations processes.

\section{Conclusions}

Polymer composites with embedded ferroelectric ceramic nano-particles were developed and examined, by employing two types of polyester resin (commercial and laboratory produced) as a matrix. Kinetic analysis took place relative to the polyesterification polymerization of the laboratory MA6AA4 polyester. Composites were developed through compression molding technique, via a thermo-compressor. Structural characterization of both types' nano- 
composites was conducted via scanning electron microscopy assisted with electron dispersive X-ray spectroscopy, infra red spectroscopy via Fourier transformation and X-ray diffraction. Morphological investigation revealed that the laboratory polyester based systems exhibit a finer dispersion of $\mathrm{BaTiO}_{3}$ nano-particles. Thermal analysis via differential scanning calorimetry was used for the detection of $T_{\mathrm{g}}$ point for all the composite systems versus barium titanate content. It was found that glass transition temperature decreases with filler content, in both types' polyester composites. Mechanical properties, such as shear and bending tests, were tested and found out that with the increase in barium titanate nano-filler, the corresponding strength values became worst. Contrariwise, dielectric properties and energy storage capability present an increase while barium titanate content increases. However, the dielectric reinforcing capability appears not to increase monotonously with ceramic filler content, implying that the optimum dielectric performance does not correspond to the maximum loaded filler. Finally, the observed dielectric relaxations were attributed, descending relaxation times, to interfacial polarization, glass to rubber transition of the polymer matrix, re-arrangement of polar side groups of the main polymer chains and motion of small parts of the macromolecular chains.

\section{References}

[1] Parthenios J., Psarras G. C., Galiotis C.: Adaptive composites incorporating shape memory alloy wires. Part 2: Development of internal recovery stresses as a function of activation temperature. Composites Part A: Applied Science and Manufacturing, 32, 1735-1747 (2001).

DOI: $10.1016 / \mathrm{S} 1359-835 \mathrm{X}(01) 00022-7$

[2] Gandhi M. V., Thompson B. S.: Smart materials and structures. Champan and Hall, London (1992).

[3] Psarras G. C.: Nanodielectrics: An emerging sector of polymer nanocomposites. Express Polymer Letters, 2, 460 (2008).

DOI: $10.3144 /$ expresspolymlett.2008.55

[4] Vinothini V., Singh P., Balasubramanian M.: Synthesis of barium titanate nanopowder using polymeric precursor method. Ceramics International, 32, 99-103 (2006).

DOI: $10.1016 /$ j.ceramint.2004.12.012
[5] Duran P., Gutierrez D., Tartaj J., Moure C.: Densification behaviour, microstructure development and dielectric properties of pure $\mathrm{BaTiO}_{3}$ prepared by thermal decomposition of $(\mathrm{Ba}, \mathrm{Ti})$-citrate polyester resins. Ceramics International, 28, 283-292 (2002). DOI: 10.1016/S0272-8842(01)00092-X

[6] Petrović M. M. V., Bobić J. D., Ramoška T., Banys J., Stojanović B. D.: Antimony doping effect on barium titanate structure and electrical properties. Ceramics International, 37, 2669-2677 (2011). DOI: $10.1016 /$ j.ceramint.2011.04.015

[7] Popielarz R., Chiang C. K., Nozaki R., Obrzut J.: Dielectric properties of polymer/ferroelectric ceramic composites from $100 \mathrm{~Hz}$ to $10 \mathrm{GHz}$. Macromolecules, 34, 5910-5915 (2001).

DOI: $10.1021 / \mathrm{ma} 001576 \mathrm{~b}$

[8] Korotkov N., Gridnev S. A., Konstantinov S. A., Klimentova T. I., Barmin Y. V., Babkina I. V.: Dielectric permittivity and conductivity of amorphous $\mathrm{PbTiO}_{3}$. Ferroelectrics, 299, 171-177 (2004).

DOI: $10.1080 / 00150190490429637$

[9] Jylhä L., Honkamo J., Jantunen H., Sihvola A.: Microstructure-based numerical modeling method for effective permittivity of ceramic/polymer composites. Journal of Applied Physics, 97, 104104/1-104104/7 (2005). DOI: $10.1063 / 1.1897071$

[10] Duran P., Tartaj J., Moure C.: Sintering behaviour and microstructural evolution of agglomerated spherical particles of high-purity barium titanate. Ceramics International, 29, 419-425 (2003).

DOI: $10.1016 / \mathrm{S} 0272-8842(02) 00154-2$

[11] Safari A., Panda R. K., Janas V. F.: Ferroelectricity: Materials, Characteristics and Applications. Advanced Ceramic Materials: Key Engineering Materials, 122124, 35-71 (1996).

DOI: 10.4028/www.scientific.net/KEM.122-124.35

[12] Schumacher B., Geßwein H., Haußelt J., Hanemann Th.: Temperature treatment of nano-scaled barium titanate filler to improve the dielectric properties of high- $k$ polymer based composites. Microelectronic Engineering, 87, 1978-1983 (2010).

DOI: $10.1016 /$ j.mee.2009.12.018

[13] Asimakopoulos I., Zoumpoulakis L., Psarras G. C.: Development and characterization of a novolac resin/ $\mathrm{BaTiO}_{3}$ nanoparticles composite system. Journal of Applied Polymer Science, 125, 3737-3744 (2012). DOI: $10.1002 /$ app.36518

[14] Abraham R., Thomas S. P., Kuryan S., Isac J., Varughese K. T., Thomas S.: Mechanical properties of ceramicpolymer nanocomposites. Express Polymer Letters, 3, 177-189 (2009). DOI: 10.3144 /expresspolymlett.2009.23

[15] Smay J. E., Cesarano S., Tuttle B. A., Lewis J. A.: Piezoelectric properties of 3-X periodic $\mathrm{Pb}\left(\mathrm{Zr}_{\mathrm{x}} \mathrm{Ti}_{1-\mathrm{x}}\right) \mathrm{O}_{3}-$ polymer composites. Journal of Applied Physics, 92, 6119-6127 (2002).

DOI: $10.1063 / 1.1513202$ 
[16] Pradhan D. K., Choudhary R. N. P., Samantaray B. K.: Studies of structural, thermal and electrical behavior of polymer nanocomposite electrolytes. Express Polymer Letters, 2, 630-638 (2008).

DOI: $10.3144 /$ expresspolymlett.2008.76

[17] Dang Z-M., Yuan J-K., Yao S-H., Liao R-J.: Flexible nanodielectric materials with high permittivity for power energy storage. Advanced Materials, 25, 63346365 (2013).

DOI: $10.1002 /$ adma.201301752

[18] Dang Z-M., Yuan J-K., Zha J-W., Zhou T., Li S-T., Hud G-H.: Fundamentals, processes and applications of high-permittivity polymer-matrix composites. Progress in Materials Science, 57, 660-723 (2012). DOI: $10.1016 /$ j.pmatsci.2011.08.001

[19] Ramajo L., Reboredo M. M., Castro M. S.: $\mathrm{BaTiO}_{3}-$ epoxy composites for electronic applications. International Journal of Applied Ceramic Technology, 7, 444451 (2010).

DOI: $10.1111 / \mathrm{j} .1744-7402.2009 .02473 . \mathrm{x}$

[20] Patsidis A. C., Psarras G. C.: Structural transition, dielectric properties and functionality in epoxy resinbarium titanate nanocomposites. Smart Materials and Structures, 22, 115006/1-115006/8 (2013).

DOI: $10.1088 / 0964-1726 / 22 / 11 / 115006$

[21] Tantis I., Psarras G. C., Tasis D.: Functionalized graphene - poly(vinyl alcohol) nanocomposites: Physical and dielectric properties. Express Polymer Letters, 6, 283-292 (2012).

DOI: 10.3144/expresspolymlett.2012.31

[22] Dang Z-M., Yu Y-F., Xu H-P., Bai J.: Study on microstructure and dielectric property of the $\mathrm{BaTiO}_{3} /$ epoxy resin composites. Composites Science and Technology, 68, 171-177 (2008).

DOI: 10.1016/j.compscitech.2007.05.021

[23] Simitzis J., Zoumpoulakis L., Soulis S.: Effect of composition and polyesterification catalysts on the optical properties of cured polyesters. Polymer International, 51, 297-307 (2002).

DOI: $10.1002 /$ pi.825

[24] Simitzis J., Zoumpoulakis L., Soulis S.: DSC curing study of catalytically synthesized maleic-acid-based unsaturated polyesters. Polymer International, 51, 308-318 (2002).

DOI: $10.1002 / \mathrm{pi} .832$

[25] Simitzis J., Zoumpoulakis L., Soulis S.: Review of the research results concerning the synthesis, curing, structure and properties of unsaturated polyesters. Current Trends in Polymer Science, 8, 107-125 (2003).

[26] Pomakis I., Simitzis I.: A new method to control the polyesterification process. Prospects of application in the production plants. Die Angewandte Makromolekulare Chemie, 99, 145-170 (1981).

DOI: $10.1002 /$ apmc.1981.050990113

[27] Orthmann H. J., Mair H. J.: Die Prūfung thermoplastischer Kunststoffe. Hanser, München (1971).
[28] Bürger A.: Kohlenstofffasern -Verstärker Polymere und deren Ehernischer. Abbaw bis zu Kohlenstoff-Verbund-werkstoffen (in German). PhD Thesis, Karlsruhe Institute of Technology (1973).

[29] Ioannou G., Patsidis A., Psarras G. C.: Dielectric and functional properties of polymer matrix $/ \mathrm{ZnO} / \mathrm{BaTiO}_{3}$ hybrid composites. Composites Part A: Applied Science and Manufacturing, 41, 104-110 (2011).

DOI: 10.1016/j.compositesa.2010.10.010

[30] Pant H. C., Patra M. K., Verma A., Vadera S. R., Kumar N.: Study of the dielectric properties of barium titanatepolymer composites. Acta Materialia, 54, 3163-3169 (2006).

DOI: $10.1016 /$ j.actamat.2006.02.031

[31] Yu C-R., Wu D-M., Liu Y., Qiao H., Yu Z-Z., Dasari A., Du X-S., Mai Y-W.: Electrical and dielectric properties of polypropylene nanocomposites based on carbon nanotubes and barium titanate nanoparticles. Composites Science and Technology, 71, 1706-1712 (2011). DOI: 10.1016/j.compscitech.2011.07.022

[32] Darwish A. G. A., Badr Y., El Shaarawy M., Shash N. M. H., Battisha I. K.: Influence of the $\mathrm{Nd}^{3+}$ ions content on the FTIR and the visible up-conversion luminescence properties of nano-structure $\mathrm{BaTiO}_{3}$, prepared by sol-gel technique. Journal of Alloys and Compounds, 489, 451-455 (2010).

DOI: $10.1016 /$ j.jallcom.2009.09.021

[33] Tangwiwat S., Milne S. J.: Barium titanate sols prepared by a diol-based sol-gel route. Journal of NonCrystalline Solids, 351, 976-980 (2005).

DOI: $10.1016 /$ j.jnoncrysol.2004.12.008

[34] Ghosh S., Dasgupta S., Sen A., Maiti H. S.: Synthesis of barium titanate nanopowder by a soft chemical process. Materials Letters, 61, 538-541 (2007). DOI: $10.1016 /$ j.matlet.2006.05.006

[35] Skoog D. A., Holler F. J., Nieman T. A.: Principles in instrumental analysis. Kostarakis, Athens (2005).

[36] Valavanides Th.: Basic principles in molecular spectroscopy and applications in organic chemistrie. Sichrona Themata, Athens (2008).

[37] McMurry J.: Organic chemistry. Crete University Publications, Herakleion (2007).

[38] Atta A. M., Nassar I. F., Bedawy H. M.: Unsaturated polyester resins based on rosin maleic anhydride adduct as corrosion protections of steel. Reactive and Functional Polymers, 67, 617-626 (2007).

DOI: $10.1016 /$ j.reactfunctpolym.2007.04.001

[39] Abdallh M., Bakir E., Yousif E.: Study the electrical conductivity of crosslinked polyester doped with different metal salts. Journal of Saudi Chemical Society, in press (2014). DOI: $10.1016 /$ j.jscs.2011.08.001

[40] Cho L. L.: Identification of textile fiber by Raman microspectroscopy. Forensic Science Journal, 6, 5562 (2007). 
[41] Oswal S. L., Pandya A. K.: Synthesis and characterization of linear aromatic polyester-amides from diacid chlorides and aminophenols. Iranian Polymer Journal, 13, 205-212 (2004).

[42] Asimakopoulos I.: Synthesis and dielectric response of composite materials polymeric matrix-barium titanate nanoparticles. Diploma Thesis, Department of Materials Science, University of Patras, Greece (2010).

[43] Kalini A., Gatos K. G., Karahaliou P. K., Georga S. N., Krontiras C. A., Psarras G. C.: Probing the dielectric response of polyurethane/alumina nanocomposites. Journal of Polymer Science Part B: Polymer Physics, 48, 2346-2354 (2010). DOI: $10.1002 /$ polb. 22120

[44] Simitzis J.: Polymers. National Technical University of Athens Press, Athens (1994).

[45] Psarras G. C., Manolakaki E., Tsangaris G. M.: Dielectric dispersion and ac conductivity in - Iron particles loaded - polymer composites. Composites Part A: Applied Science and Manufacturing, 34, 1187-1198 (2003). DOI: 10.1016/j.compositesa.2003.08.002

[46] Psarras G. C., Manolakaki E., Tsangaris G. M.: Electrical relaxations in polymeric particulate composites of epoxy resin and metal particles. Composites Part A: Applied Science and Manufacturing, 33, 375-384 (2002). DOI: $10.1016 / \mathrm{S} 1359-835 \mathrm{X}(01) 00117-8$

[47] Tsangaris G. M., Psarras G. C., Kouloumbi N.: Electric modulus and interfacial polarization in composite polymeric systems. Journal of Materials Science, 33, 2027-2037 (1998). DOI: 10.1023/A:1004398514901
[48] Kontos G. A., Soulintzis A. L., Karahaliou P. K., Psarras G. C., Georga S. N., Krontiras C. A., Pisanias M. N.: Electrical relaxation dynamics in $\mathrm{TiO}_{2}-$ polymer matrix composites. Express Polymer Letters, 1, 781789 (2007).

DOI: 10.3144/expresspolymlett.2007.108

[49] Patsidis A. C., Kalaitzidou K., Psarras G. C.: Dielectric response, functionality and energy storage in epoxy nanocomposites: Barium titanate vs exfoliated graphite nanoplatelets. Materials Chemistry and Physics, 135, 798-805 (2012).

DOI: 10.1016/j.matchemphys.2012.05.060

[50] Dang Z-M., Yuan J-K., Zha J-W., Zhou T., Li S-T., Hu G-H.: Fundamentals, processes and applications of high-permittivity polymer-matrix composites. Progress in Materials Science, 57, 660-723 (2012). DOI: $10.1016 / \mathrm{j}$. pmatsci.2011.08.001

[51] Patsidis A., Psarras G. C.: Dielectric behaviour and functionality of polymer matrix - ceramic $\mathrm{BaTiO}_{3}$ composites. Express Polymer Letters, 2, 718-726 (2008). DOI: 10.3144/expresspolymlett.2008.85

[52] Patsidis A. C., Kalaitzidou K., Psarras G. C.: Carbon or barium titanate reinforced epoxy resin nanocomposites: Dielectric, thermomechanical and functional behaviour. Journal of Advanced Physics, 2, 7-12 (2013). DOI: 10.1166/jap.2013.1040

[53] Mathioudakis G. N., Patsidis A. C., Psarras G. C.: Dynamic electrical thermal analysis on zinc oxide/ epoxy resin nanodielectrics. Journal of Thermal Analysis and Calorimetry, 116, 27-33 (2014). DOI: $10.1007 / \mathrm{s} 10973-013-3510-8$ 